\title{
Why obese children cannot resist food: the role of impulsivity
}

Citation for published version (APA):

Nederkoorn, C., Braet, C., Eijs, Y. V., Tanghe, A., \& Jansen, A. T. M. (2006). Why obese children cannot resist food: the role of impulsivity. Eating Behaviors, 7, 315-322.

https://doi.org/10.1016/j.eatbeh.2005.11.005

Document status and date:

Published: 01/01/2006

DOI:

10.1016/j.eatbeh.2005.11.005

Document Version:

Publisher's PDF, also known as Version of record

Document license:

Taverne

Please check the document version of this publication:

- A submitted manuscript is the version of the article upon submission and before peer-review. There can be important differences between the submitted version and the official published version of record.

People interested in the research are advised to contact the author for the final version of the publication, or visit the DOI to the publisher's website.

- The final author version and the galley proof are versions of the publication after peer review.

- The final published version features the final layout of the paper including the volume, issue and page numbers.

Link to publication

\footnotetext{
General rights rights.

- You may freely distribute the URL identifying the publication in the public portal. please follow below link for the End User Agreement:

www.umlib.nl/taverne-license

Take down policy

If you believe that this document breaches copyright please contact us at:

repository@maastrichtuniversity.nl

providing details and we will investigate your claim.
}

Copyright and moral rights for the publications made accessible in the public portal are retained by the authors and/or other copyright owners and it is a condition of accessing publications that users recognise and abide by the legal requirements associated with these

- Users may download and print one copy of any publication from the public portal for the purpose of private study or research.

- You may not further distribute the material or use it for any profit-making activity or commercial gain

If the publication is distributed under the terms of Article $25 \mathrm{fa}$ of the Dutch Copyright Act, indicated by the "Taverne" license above, 


\title{
Why obese children cannot resist food: The role of impulsivity
}

\author{
Chantal Nederkoorn ${ }^{\mathrm{a}, *}$, Caroline Braet ${ }^{\mathrm{b}}$, Yvonne Van Eijs ${ }^{\mathrm{a}}$, Ann Tanghe ${ }^{\mathrm{c}}$, Anita Jansen ${ }^{\mathrm{a}}$ \\ a Department of Experimental Psychology, Maastricht University, the Netherlands \\ ${ }^{\mathrm{b}}$ Department of Developmental Personality and Social Psychology, Ghent University, Belgium \\ c Zeepreventorium, Health Centre De Haan, Belgium
}

Received 7 June 2005; received in revised form 27 October 2005; accepted 1 November 2005

\begin{abstract}
Facing the undesirable health consequences of being obese, an important question is why some people are not able to resist eating to excess. It is theorized that increased impulsivity at least partly underlies the inability to control eating behaviour; being more impulsive is supposed to make it more difficult to resist food intake. Thirty-three obese children in a residential setting and 31 lean control children are tested. Impulsivity is measured with two behavioural measures (inhibitory control and sensitivity to reward) and questionnaires. Results show that the obese children in treatment were more sensitive to reward and showed less inhibitory control than normal weight children. In addition, the obese children with eating binges were more impulsive than the obese children without eating binges. Most interesting finding was that the children that were the least effective in inhibiting responses, lost less weight in the residential treatment program. To conclude: impulsivity is a personality characteristic that potentially has crucial consequences for the development and maintenance, as well as treatment of obesity.
\end{abstract}

(C) 2005 Elsevier Ltd. All rights reserved.

Keywords: Obesity; Impulsivity; Inhibitory control; Sensitivity to reward; Children

\section{Introduction}

Most parts of the world are nowadays characterised by food abundance, and the increased energy supply is closely associated with increasing BMIs. While our body is equipped for times of scarcity, we are constantly surrounded by plenty of fat, high caloric and tasty snacks. That is why, for many people, energy intake exceeds energy expenditure and the consequences are well known: the mean BMI of people in the Western European countries, Australia, USA and China increases rapidly (Silvertoinen et al., 2004). Although mean BMI of the populations increases, the dispersion is large: an increasing part of the population is overweight, obese or even morbid obese, while others stay lean. Yet within these societies, everyone is exposed to the same profusion of food, so an important question is why are there so many individual differences? Besides the influence of metabolism and build, behaviour has a large influence on the variation in body weight. Physical activity, watching television and a sedentary lifestyle are related to weight (Davison \& Birch, 2004; Janssen, Katzmarzyk, Boyce, King, \& Pickett, 2004). Furthermore, obese people are found to show a preference for energy dense, high-fat food (Schrauwen \& Westerterp, 2000; Seidell, 1998; Skinner,

\footnotetext{
* Corresponding author. Department of Experimental Psychology, Faculty of Psychology, Maastricht University, P.O. Box 616, 6200 MD Maastricht, the Netherlands. Tel.: +31 43 3881925; fax: +31 433884196.

E-mail address: c.nederkoorn@psychology.unimaas.nl (C. Nederkoorn).
} 
Bounds, Carruth, Morris, \& Ziegler, 2004) and eat more of these fatting foods compared to lean people (Cutting, Fisher, Grimm-Thomas, \& Birch, 1999; Ebbeling et al., 2004; Fischer \& Birch, 1995; Halford, Gillespie, Brown, Pontin, \& Dovey, 2004; Johnson \& Birch, 1994; Stubbs \& Lee, 2004). Besides eating more, obese children seem more vulnerable for food triggers, like the smell and taste of food, than lean children and they respond with increased food intake to these triggers (Jansen et al., 2003). So for obese people it is more difficult to resist the temptation of tasty food than for lean people, despite the negative consequences of overeating for health and quality of life. An important question is why.

Research suggests that obese people have more deficits in impulse control than lean people. Obese people in weight reduction programs score higher on trait impulsivity questionnaires and engage more often in impulsive behaviours, like substance abuse, than lean people do (Chalmers, Bowyer, \& Olenick, 1990; Rydén et al., 2003, 2004; Williamson, Kelley, Davis, Ruggiero, \& Blouin, 1985). Within a sample of obese people, obese binge eaters appeared more impulsive than obese women without eating binges (De Zwaan et al., 1994; Nasser, Gluck, \& Geliebter, 2004).

It is not only in self-reports that obese people are found to be more impulsive than lean people. Behavioural tasks like the delay of gratification paradigm in which people have to choice between a smaller, direct reward and a larger delayed reward, showed that it was more difficult for obese than normal weight children to wait for a larger delayed reward (Bonato \& Boland, 1983; Johnson, Parry, \& Drapman, 1978; Lewittes \& Israel, 1978; Sigal \& Adler, 1976, but see Bourget \& White, 1981; Geller, Keane, \& Scheirer, 1981). In line with this, it was found that BMI in adult women (ranging from lean to obese) predicted a preference for immediate reward (Davis, Levitan, Muglia, Bewell, \& Kennedy, 2004). In this study, participants play a gamble task on the computer. Participants with higher BMI more often choose for high immediate gain and larger future losses in a gamble task, instead of lower immediate gain and smaller future loss, indicating poor and impulsive decision making.

A third line of evidence for a link between obesity and impulsivity is the comorbidity between obesity and attention deficit/hyperactivity disorder (ADHD) in children. Obese children in treatment are found to have a much higher incidence of ADHD (58\%) than in the general population (10\%) (Agranat-Meged et al., 2005). Moreover, Holtkamp et al (2004) found that, contrary to their hypotheses, children with ADHD had higher BMIs compared to reference values, and their ADHD sample included twice as much participants with obesity as expected.

Interestingly, increased impulsivity has been found to predicts weight loss failure during therapy (Jönnson, Björvell, Levander, \& Rössner, 1986) and it also predicts the dropouts in a weight-loss program (Hjördis \& Gunnar, 1989).

Other eating disorders in which overeating is an important aspect, like bulimia nervosa, are also associated with increased impulsiveness (Claes, Vandereyken, \& Vertommen, 2002; Loxton \& Dawe, 2001; Steiger et al., 2001). Although experimental research on impulsivity in bulimic participants is scarce, a few studies were done. Ferraro, Wonderlich, and Jocic (1997) found that bulimics showed more impulsivity deficits on neuropsychological tests than controls. In another study, Ferraro, Wonderlich, and Johnson (1997) used a negative priming task to measure inhibitory control and found that subjects at risk for an eating disorder failed to show an inhibitory effect of negative primes, thereby demonstrating less inhibitory control. Kane, Loxton, Staiger, and Dawe (2004) used a behavioural measure of reward responsiveness (speed of card sorting with and without financial reward) as an index of impulsivity and found that bulimic women were more responsive to reward. Nederkoorn, Van Eijs, and Jansen (2004) found that subjects with bulimic symptoms were less effective in response inhibition during the stop signal task. These findings suggest a general impulsivity problem in disorders concerning overeating, including bulimia nervosa, binge eating disorder and obesity.

In obesity research, the measures used for impulsivity are diverse and mostly based on self reports, which are susceptible for demand characteristics and limited self-knowledge. A second problem is that impulsivity is a broad concept and includes many definitions and operationalizations. Correlations between different measures of impulsivity are low (Barkley, 1991). The research on impulsivity shows two major foci: a motivational focus and an inhibition focus (Doughterty et al., 2003; Solanto et al., 2001). In the motivational approach, a sensitivity to reward and an intolerance for delay of reward are key factors. The motivational focus originates from the study of operant behaviour of animals. People are considered impulsive if they prefer immediate smaller reward over larger delayed rewards even if this is smaller. In his neuropsychological model, Gray $(1982,1987)$ demonstrated that sensitivity to reward is an important determinant of impulsivity. According to his theory, motivated behaviour is mediated by two systems, the behavioural activation system (BAS) and the behavioural inhibition system (BIS). The BAS regulates appetitive and reward-seeking behaviour and increases motor output. The counterpart of this system, the BIS, is active 
in passive avoidance of punishment and non-reward and decreases motor output. Individual differences in personality can be reduced to variations in the relative strength of the two systems: impulsive people have a relative stronger BAS than BIS, while anxiety prone people have a relative stronger BIS than BAS.

The second focus states that deficits in inhibitory control are in the heart of impulsive disorders (Barkley, 1997). In Barkley's model, behavioural inhibition is necessary for executive functions like the working memory, regulation of affect, motivation, arousal and behavioural analyses. These executive functions contribute to the self-regulation of behaviour and create a delay in which one can think before acting. Lack of response inhibition therefore causes impulsive behaviour.

In sum, some studies suggest that obese people are more impulsive, alike other overeaters. Increased impulsivity might make it more difficult for them to resist the temptation of tasty food. Therefore, impulsivity is expected to play a role in both the development and maintenance of obesity. Research is however scarce, in particular experimental and behavioural research which is not primarily based on self-reports. Moreover, impulsivity is a multidimensional construct, which suggests that diverse aspects should be taken into account. In this study, two behavioural paradigms were used to test whether obese children are more impulsive than their lean counterparts. The first task is based on the motivational focus and the second one on the inhibition focus. In addition, a self-report measure of impulsivity and an impulsivity rating by the teacher were used. It is hypothesized that the obese children are more sensitive to reward than to punishment (have a relative dominant BAS) and have less inhibitory control than the normal weight children. In addition, the obese children with eating binges were expected to be more impulsive compared to obese children without eating binges. Finally, because impulsivity has been found to prevent weight loss (Jönnson et al., 1986), it was hypothesized that the most impulsive obese children would be less successful in losing weight during treatment.

\section{Method}

\subsection{Participants}

The experimental group consisted of 32 children, receiving a one-year multidisciplinary residential treatment for obesity (Braet, Van Winckel, Tanghe, de Bode, \& Franckx, 2003). The treatment is focused on medical care, physical activity, diet management and psychological and social support. All the children attended secondary school in the residence. Fifteen children reported at least 1 eating binge during the last four weeks before the start of the treatment (as measured with the EDE-Q prior to the treatment), and 15 children reported no binges at all (of 2 children, these data were not available). The 31 normal weight control children were selected from a regular secondary school. They were matched on age, gender and level of secondary education and with the children in the experimental group. The obese children had a significant higher BMI, compared to the control children $(t(61)=.1, p<.001)$. The obese binge eaters and non-binge eaters did not differ on BMI $(t(28)<1)$. Participant characteristics are summarized in Table 1.

\subsection{Measures}

The door opening task was a slightly adjusted version of the task of Matthys, van Goozen, de Vries, CohenKettenis, \& van Engeland, 1998). The task has shown to differentiate between normal children and children with

Table 1

Gender, level of secondary education, age (mean and range) and BMI during start treatment and during the experiment (mean and SD) of lean control children and obese children

\begin{tabular}{|c|c|c|c|c|}
\hline & Control group & Obese group & Obese binge eaters & Obese non-binge eaters \\
\hline$n$ & 31 & 32 & 15 & 15 \\
\hline Boy/girl & $12 / 19$ & $13 / 19$ & $5 / 10$ & $6 / 9$ \\
\hline Level of education: low/middle/high ${ }^{\mathrm{a}}$ & $4 / 13 / 14$ & $4 / 12 / 16$ & $2 / 6 / 7$ & $1 / 6 / 8$ \\
\hline Age & $13.7(13-15)$ & $13.7(12-15)$ & $13.7(12-15)$ & $13.9(12-15)$ \\
\hline BMI test & $19.3(2.0)$ & $26.6(4.2)^{* *}$ & $27.8(3.6)$ & $25.8(4.3)$ \\
\hline BMI start treatment & & $33.0(4.0)$ & $33.0(4.3)$ & $33.5(4.4)$ \\
\hline
\end{tabular}

In addition, the obese children are subdivided into binge eaters and non binge eaters ${ }^{\mathrm{b}}{ }^{* *} p<.01$.

${ }^{\text {a }}$ In Belgium, secondary school is subdivided in 3 subtypes, low $=$ vocational education, middle $=$ technical education, high $=$ general education .

${ }^{\mathrm{b}}$ Of two obese boys, data on binge eating behavior was missing. 
impulsive disorders like attention deficit hyperactivity disorder (ADHD) and conduct disorder (CD) (Daughtery \& Quay, 1991; Matthys et al., 1998; Shapiro, Quay, Hogan, \& Schwartz, 1988). In this computer task, children can open a virtual door by pressing a bar and find a happy or a sad face behind the door. A sad face means they lose a point, a happy face means they win a point. There are 100 doors in total and the probability that the children find a happy face and earn a point when they open a door decreases from $90 \%$ to $0 \%$ per 10 -doors block. Each child started with 10 points and practised once with a happy face and once with a sad face. The children were explained that they could either take a chance and open a door or stop the game and cash in the points they earned so far. They were told that the more points they earned, the more presents they would get. The dependent variable in this task was the number of doors opened, which is considered as a measure of response perseveration. Response perseveration has been defined as the tendency to continue a response set for reward (BAS activation) despite punishment (BIS activation) (Matthys et al., 1998). Thus, impulsive participants with a relative dominant BAS will continue to open doors even in the face of losing points. Participants with a relative dominant BIS, who are more sensitive to punishment, will stop opening doors after a few experiences of punishment.

The stop signal task, designed to measure disinhibition, was copied from Logan, Schachar, \& Tannock (1997). This task has been related to impulsivity (Logan et al., 1997) and impulsive disorders like ADHD (Schachar, Tannock, Marriot, \& Logan, 1995). The stop signal task involves two concurrent tasks, a go task, which is a choice reaction time task, and a stop task, occurring on $25 \%$ of the trails and involving a stop signal that tells subjects to inhibit their responses to the go task. The task consists of five blocks, each containing 64 trials. During the go trials, the letters $\mathrm{O}$ or $\mathrm{X}$ are presented for $1500 \mathrm{~ms}$ on the centre of a PC computer screen, preceded by a $500 \mathrm{~ms}$ fixation point. The subject had to press a right button with his right hand when an $\mathrm{X}$ was on the screen and a left button with his left hand when an $\mathrm{O}$ was on the screen. Between trials, the screen was blank for $1000 \mathrm{~ms}$. The subject was instructed to press the buttons as fast as possible. The stop signal was a $100 \mathrm{~ms}, 1000 \mathrm{~Hz}$ tone, produced by the computer. Initially, the stop signal delay was set at $250 \mathrm{~ms}$ after the presentation of the go signal (the $\mathrm{O}$ or the $\mathrm{X}$ ) and then adjusted dynamically dependent on the responses of the subject. When the subject failed to inhibit the response, the delay was decreased by $50 \mathrm{~ms}$, thereby making it easier to inhibit the next stop signal trial. When the subject succeeded in inhibiting the response, the delay was increased by $50 \mathrm{~ms}$, thereby making it more difficult to inhibit the next stop signal trial. The two variables measured in this task are reaction time (RT) and stop delay. The stop signal reaction time (SSRT) is calculated by subtracting the stop delay from the reaction time. Higher stop signal reaction times means less inhibitory control.

The BIS/BAS scales (Carver \& White, 1994) were translated in Dutch and adjusted for use with children. The questionnaire consists of 20 items, and yields four scales, one BIS (higher scores mean higher anxiety) and three BAS scales, namely Reward Responsiveness (RR), Drive (DRV) and Fun Seeking (FS) (higher scores mean higher impulsivity). The reliability of the scales is moderate (internal consistency: $\alpha$ ranging from 0.65 to 0.80 and test-retest reliability: $r$ ranging from .59 to .69 , Carver \& White, 1994; Jorm et al., 1999). The BAS scales are found to correlate with theoretical related constructs, like extraversion, reward dependence and novelty-seeking, while the BIS scale has found to correlate with related constructs like harm avoidance and anxiety (Carver \& White, 1994).

The Hyperactivity/Impulsivity subscale of the Disruptive Behavior Disorder Rating Scale (Oosterlaan, Scheres, Antrop, Roeyers, \& Sergeant, 2000; Pelham, Gnagy, Greenslade, \& Milich, 1992) was used to measure impulsive behaviour in school. The scale is completed by the teacher of the children and exists of 9 items with a 4 point scale. Higher scores mean more impulsive behaviours. This scale proved to have good predictive power for ADHD (Pelham et al., 1992) and good to moderate psychometric properties (Oosterlaan et al., 2000).

A Dutch translation of the $E D E-Q$ (Fairburn \& Beglin, 1994) was used to measure to existence of specific eating psychopathology. One item refers to number of eating binges during the last 28 days and this item is used to divide groups in either having no eating binges, or 1 or more eating binges (median split).

\subsection{Procedure}

All children were tested individually in a separate room during school lessons. The children started with the dooropening task. The points they won during this task were registered and the children were promised a present after the next task, the stop signal task. During the stop signal task, the children were explicitly instructed to respond as fast as possible on the choice reaction time task, and they were explained to inhibit their response when hearing a tone. They were made clear that they always had to push the buttons as fast as possible and that they should not wait for the tone. 
Table 2

Means and standard deviation (SD) on several measures of impulsivity

\begin{tabular}{lcccc}
\hline & Control group & Obese children & Obese binge eaters & Obese non-binge eaters \\
\hline$n$ & 31 & 32 & 15 & 15 \\
$\begin{array}{l}\text { Door opening task } \\
\quad \text { Number of doors }\end{array}$ & & & \\
Stop signal task & $39.4(20.9)$ & $54.0(24.8)^{*}$ & $65.2(23.6)$ & $47.2(21.1)^{*}$ \\
$\quad$ SSRT & $166.4(35.7)$ & $186.9(43.5)^{*}$ & $180.1(42.7)$ & $194.9(46.8)$ \\
$\quad$ RT & $575.5(168.5)$ & $534.6(98.7)$ & $527.9(85.9)$ & $545.2(117.1)$ \\
BIS/BAS scales & & & & \\
$\quad$ BAS DR & $9.2(2.8)$ & $8.4(2.0)$ & $8.2(2.0)$ & $8.5(2.2)$ \\
$\quad$ BAS FS & $7.1(1.6)$ & $8.0(2.0)^{*}$ & $7.7(1.9)$ & $8.3(2.1)$ \\
$\quad$ BAS RR & $8.1(1.9)$ & $9.0(2.5)$ & $8.8(2.2)$ & $8.8(2.2)$ \\
$\quad$ BAS total & $24.3(4.1)$ & $25.4(5.1)$ & $24.9(5.8)$ & $25.7(4.5)$ \\
$\quad$ BIS & $16.6(3.8)$ & $15.1(3.7)$ & $3.5(4.4)$ & $15.5(3.9)$ \\
Hyperactivity/impulsivity subscale & $2.0(4.7)$ & $2.6(3.9)$ & $2.1(3.8)$ \\
\hline
\end{tabular}

The obese children are tested statistically to the lean children. In addition, the obese children are subdivided into binge eaters and non binge eaters, which are tested statistically against each other. ${ }^{*} p<.05$.

After both tasks the children were invited to choose presents (two presents if they earned less then 30 points in the door-opening task, three presents if they earned more then 30 points) and finally they completed the BIS/BAS scales.

\section{Results}

The first hypothesis states that obese children are more sensitive to reward and keep gambling longer in the dooropening task than normal weight children. This hypothesis was confirmed: the obese children opened significant more doors in the door-opening task than the control group $(t(60)=2.51, p<.05$; see Table 2).

Furthermore, it was hypothesized that the obese children would show less inhibitory control on the stop signal task, and this hypothesis was also confirmed. The obese children had significant longer SSRTs than the control children $(t(60)=4.1, p<.05)$. No significant differences between the groups were found on reaction times on the go-trials $(t(60)=1.2)$, indicating that there were no impairments in responding itself.

The third hypothesis states that on self-report measures, the obese children would score higher on BAS sensitivity and lower on BIS sensitivity. It appeared that obese children scored marginally significant higher on the BAS Fun Seeking subscale $(t(60)=2.0, p=.053)$. No differences on the other BIS and BAS subscales were found $(t(60)<1.6$; see Table 2).

Fourth, it was explored if obese children behaved more hyperactive or impulsive during school. However, no differences between the teachers' ratings of obese and control children are found $(t(60)<1)$.

In addition, it was hypothesized that binge eaters are more impulsive than the non binge eaters. The binge eaters indeed gambled significantly longer than the non-binge eaters $(t(28)=2.2, p<.05)$. The obese binge eaters and nonbinge eaters did not differ from each other on inhibitory control in the stop signal task or on the other measures $(t(28)<1)$.

Finally, it was tested if the most impulsive children had been less successful in losing weight during treatment. A significant negative correlation between the SSRTs on the stop signal task and weight loss (percentage BMI decline) was found $(r=-.49, p<.05),{ }^{1}$ meaning that the children with the least inhibitory control were the least successful weight losers. In general, the children were highly successful in BMI decline: they had lost $24 \%$ of their initial BMI, while the program was not yet finished.

\section{Discussion}

In this study, it was hypothesized (1) that obese children are more sensitive to reward than to punishment (have a relative dominant BAS) and have less inhibitory control than the normal weight children, (2) that the obese children

\footnotetext{
${ }^{1}$ Only the children who were at least 6 months in treatment were entered in this analysis, $n=22$.
} 
with eating binges are more impulsive than the obese children without eating binges, and (3) that the most impulsive obese children were less successful in losing weight during treatment. Two paradigms were used to test if obese children in a treatment program are more impulsive than lean children. The results support the hypotheses: the obese children gambled longer in the door opening task, a measure of sensitivity to reward and relative dominance of the BAS over BIS, and they showed longer SSRTs in the stop signal task, which means that they had less inhibitory control as normal children. The results on the self-report measures point to higher fun seeking scores in obese children. The converging results are robust and point to significantly increased impulsivity in our sample of obese children as compared to lean children.

The obese children who reported eating binges before treatment, appeared to be more sensitive to reward then the obese children without eating binges. No differences between the subgroups were found on the other measures of impulsivity. This is partly in line with earlier findings of obese binge eaters being more impulsive then obese nonbingers (De Zwaan et al., 1994; Nasser et al., 2004).

A most important finding was that response inhibition was significantly related to weight loss: worse response inhibition meant less weight loss during treatment. Since impulsivity appears a stable personality trait (Rydén et al., 2004), this might mean that the treatment was not as effective for the most impulsive children as for children with better inhibitory control. Perhaps it is more difficult to follow treatment instructions and strict eating rules for the most impulsive children. Although the children were on an externally controlled diet, there were possibilities to break diet rules, both within the residence and during weekend leaves. However, since this finding is correlational in nature, the causal interpretation remains speculative. Experimental or longitudinal research is needed to entangle the relation between impulsivity and treatment outcome.

So far, the conclusion is that the obese children in this study showed a basic problem with impulse control: they were more sensitive to reward and they were not able to inhibit ongoing motor responses, compared to lean children. This is in line with the research on delayed gratification, where obese children were found to have a preference for a smaller immediate reward over a larger delayed reward, compared to lean children. Although in some studies, this preference was specific for food rewards (Bonato \& Boland, 1983; Johnson et al., 1978), in other studies the obese children also had difficulties to delay non-food gratifications (Sigal \& Adler, 1976). In the current study, the obese children appear to have a general problem with impulsivity: they showed a preference for a neutral reward and their inability to inhibit their responses was unrelated to food cues. This suggests that the problem in obese children is not restricted to food items. This can also explain the comorbidity with ADHD, which is found in hospitalized obese children (Agranat-Meged et al., 2005). Note that the sample in the study on hand was also compound of hospitalized children. It is possible that hospitalized obese children form a subgroup with more intense and general impulsivity problems.

The obese children with eating binges were more sensitive to reward than the obese children without binges. Most intriguing is that increased levels of impulsivity were related to less weight loss and appeared to be a hindrance to treatment. It sounds plausible that increased impulsivity makes it more difficult to resist tasty, energy dense food.

The treatment itself was highly effective in reducing weight (BMI was reduced with $24 \%$ while treatment was not yet finished). However, a major question is if this weight reduction can be maintained, when the diet is no longer under supervised control. An outcome study of this specific treatment (Braet et al., 2003) showed that after 14 months, $50 \%$ of the children showed an increase of BMI of less than $10 \%$, compared to post treatment, which means that their weight is fairly stable. The other $50 \%$ showed an increase of $10 \%$ to $41 \%$ of BMI after treatment. Although all children (except one) in this study had less overweight after 14 months compared to pre-treatment, this means that relapse is substantial. Therefore, a main empirical question for further research is how impulsivity can be addressed in obesity treatment, thereby enabling the most impulsive obese people to lose weight like the non-impulsive obese people.

\section{References}

Agranat-Meged, A. N., Deitcher, C., Goldzweig, G., Leibson, L., Stein, M., \& Galili-Weisstub, E. (2005). Childhood obesity and attention deficit/ hyperactivity disorder: A newly described comorbidity in obese hospitalized children. International Journal of Eating Disorders, 37, $357-359$.

Barkley, R. A. (1991). The ecological validity of laboratory and analogue assessment methods of ADHD symptoms. Journal of Abnormal Child Psychology, 19, 149-178.

Barkley, R. A. (1997). Behavioral inhibition, sustained attention, and executive functions: Constructing a unifying theory of ADHD. Psychological Bulletin, 121, 65-94.

Bonato, D. P., \& Boland, F. J. (1983). Delay of gratification in obese children. Addictive Behaviors, 8, 71-74. 
Bourget, V., \& White, D. R. (1981). Performance of overweight and normal-weight girls on delay of gratification tasks. International Journal of Eating Disorders, 3, 63-71.

Braet, C., Van Winckel, M., Tanghe, A., de Bode, P., \& Franckx, H. (2003). Inpatient treatment of obese children: A multicomponent program without stringent calorie restriction. European Journal of Pediatrics, 162, 391-396.

Carver, C. S., \& White, T. L. (1994). Behavioral inhibition, behavioral activation, and affective responses to impending reward and punishment: The BIS/BAS scales. Journal of Personality and Social Psychology, 67, 319-333.

Chalmers, D. K., Bowyer, C. A., \& Olenick, N. L. (1990). Problem drinking and obesity: A comparison in personality patterns and life-style. International Journal of the Addictions, 25, 803-817.

Claes, L., Vandereyken, W., \& Vertommen, H. (2002). Impulsive and compulsive traits in eating disordered patients compared with controls. Personality and Individual Differences, 32, 707-714.

Cutting, T. M., Fisher, J. O., Grimm-Thomas, K., \& Birch, L. L. (1999). Like mother, like daughter: Familial patterns of overweight are mediated by mothers' dietary disinhibition. American Journal of Clinical Nutrition, 69, 608-613.

Daughtery, T. K., \& Quay, H. C. (1991). Response perseveration and delayed responding in childhood behavior disorders. Journal of Child Psychology and Psychiatry, 32, 453-461.

Davis, C., Levitan, R. D., Muglia, P., Bewell, C., \& Kennedy, J. L. (2004). Decision-making deficits and overeating: A risk model for obesity. Obesity Research, 12, 929-935.

Davison, K. K., \& Birch, L. L. (2004). Lean and weight stable: Behavioral predictors and psychological correlates. Obesity Research, $12,1085-1093$.

De Zwaan, M., Mitchell, J. E., Seim, H. C., Specker, S. M., Pyle, R. L., Raymond, N. C., et al. (1994). Eating related and general psychopathology in obese females with binge eating disorder. International Journal of Eating Disorders, 15, 43-52.

Doughterty, T. K., Bjork, J. M., Harper, R. A., Marsh, D. M., Moeller, F. G., Mathias, C. W., et al. (2003). Behavioral impulsivity paradigms: A comparison in hospitalized adolescents with disruptive behavior disorders. Journal of Child Psychology and Psychiatry, 44, $1145-1157$.

Ebbeling, C. B., Sinclair, K. B., Pereira, M. A., Garcia-Lago, E., Feldman, H. A., \& Ludwig, D. S. (2004). Compensation for energy intake from fast food among overweight and lean adolescents. Journal of the American Medical Association, 291, 2828-2833.

Fairburn, C. C., \& Beglin, S. J. (1994). The assessment of eating disorders: Interview or self-report questionnaire? International Journal of Eating Disorders, 16, 363-370.

Ferraro, F. R., Wonderlich, S., \& Jocic, Z. (1997). Performance variability as a new theoretical mechanism regarding eating disorders and cognitive processing. Journal of Clinical Psychology, 53, 117-121.

Ferraro, F. R., Wonderlich, S., \& Johnson, K. (1997). Do individuals at risk for eating disorders exhibit negative priming deficits? Journal of General Psychology, 124, 381-390.

Fischer, J. O., \& Birch, L. L. (1995). Fat preferences and fat consumption of 3- to 5-year children are related to parental adiposity. Journal of the American Dietetic Association, 95, 759-764.

Geller, S. E., Keane, T. M., \& Scheirer, C. J. (1981). Delay of gratification, locus of control, and eating patterns in obese and nonobese children. Addictive Behaviors, 6, 9-14.

Gray, J. A. (1982). The neuropsychology of anxiety: An enquiry of the septo-hippocampal system. Oxford: Oxford University Press.

Gray, J. A. (1987). Perspectives on anxiety and impulsivity: A commentary. Journal of Research in Personality, 21, $493-509$.

Halford, J. C., Gillespie, J., Brown, V., Pontin, E. E., \& Dovey, T. M. (2004). Food advertisements induce food consumption in both lean and obese children. Obesity Research, 12, 171.

Hjördis, B., \& Gunnar, E. (1989). Characteristics of drop-outs from a long-term behavioral treatment program for obesity. International Journal of Eating Disorders, 8, 363-368.

Holtkamp, K., Konrad, K., Muller, B., Heussen, N., Herpertz, S., Herpertz-Dahlmann, B., et al. (2004). Overweight and obesity in children with Attention-Deficit/Hyperactivity Disorder. Internation Journal of Obesity, 28, 685-689.

Jansen, A., Theunissen, N., Slechten, K., Nederkoorn, C., Boon, B., Mulkens, S., et al. (2003). Overweight children overeat after exposure to food cues. Eating Behaviors, 4, 197-209.

Janssen, I., Katzmarzyk, P. T., Boyce, W. F., King, M. A., \& Pickett, W. (2004). Overweight and obesity in Canadian adolescents and their associations with dietary habits and physical patterns. Journal of Adolescent Health, 35, 360-367.

Johnson, S. L., \& Birch, L. L. (1994). Parents' and children's adiposity and eating style. Pediatrics, 94, 653-661.

Johnson, W. G., Parry, W., \& Drapman, R. S. (1978). The performance of obese and normal size children on a delay of gratification task. Addictive Behaviors, 3, 205-208.

Jönnson, B., Björvell, H., Levander, S., \& Rössner, S. (1986). Personality traits predicting weight loss outcome in obese patients. Acta Psyciatrica Scandinavia, 74, 384-387.

Jorm, A. F., Christensen, H., Henderson, A. S., Jacomb, P. A., Korten, P. A., \& Rodgers, B. (1999). Using the BIS/BAS scales to measure behavioural inhibition and behavioural activation: Factor structure, validity and norms in a large community sample. Personality and Individual Differences, 26, 49-58.

Kane, T. A., Loxton, N. J., Staiger, P. K., \& Dawe, S. (2004). Does the tendency to act impulsively underlie binge eating and alcohol use problems? An empirical investigation. Personality and Individual Differences, 36, 83-94.

Lewittes, D. J., \& Israel, A. C. (1978). Maintaining children's ongoing delay of gratification through other-oriented consequences. Developmental Psychology, 14, 181-182.

Logan, G. D., Schachar, R. J., \& Tannock, R. (1997). Impulsivity and inhibitory control. Psychological Science, 8, $60-64$.

Loxton, N. J., \& Dawe, S. (2001). Alcohol abuse and dysfunctional eating in adolescent girls: The influence of individual differences in sensitivity to reward and punishment. International Journal of Eating Disorders, 29, 409-416.

Matthys, W., van Goozen, S. H. M., de Vries, H., Cohen-Kettenis, P. T., \& van Engeland, H. (1998). Journal of Child Psychology and Psychiatry, 5 , $643-651$. 
Nasser, J. A., Gluck, M. E., \& Geliebter, A. (2004). Impulsivity and test meal intake in obese binge eating women. Appetite, 43, $303-307$. Nederkoorn, C., Van Eijs, Y., \& Jansen, A. (2004). Restrained eaters act on impulse. Personality and Individual Differences, 37, $1651-1658$.

Oosterlaan, J., Scheres, A., Antrop, I., Roeyers, H., \& Sergeant, J. A. (2000). Vragenlijst voor Gedragsproblemen bij Kinderen (VvGK). Nederlandse bewerking van de Disruptive Behavior Disorder Rating Scale [Dutch translation of the Disruptive Behavior Disorders Rating Scale]. Lisse: Swets Test Publishers.

Pelham, W., Gnagy, E. M., Greenslade, K. E., \& Milich, R. (1992). Teacher ratings of DSM-III-R symptoms for the disruptive behavior disorders Journal of the American Academy of Child and Adolescent Psychiatry, 31, 210-218.

Rydén, A., Sullivan, M., Torgerson, J. S., Karlsson, J., Lindroos, A. -K., \& Taft, C. (2003). Severe obesity and personality: A comparative controlled study of personality traits. International Journal of Obesity, 27, 1534-1540.

Rydén, A., Sullivan, M., Torgerson, J. S., Karlsson, J., Lindroos, A. -K., \& Taft, C. (2004). A comparative controlled study of personality in severe obesity: A 2-y follow-up after intervention. International Journal of Obesity, 28, 1485-1493.

Schachar, R., Tannock, R., Marriot, M., \& Logan, G. (1995). Deficient inhibitory control in attention deficit hyperactivity disorder. Journal of Abnormal Child Psychology, 23, 411-437.

Schrauwen, P., \& Westerterp, K. R. (2000). The role of high-fat diets and physical activity in the regulation of body weight. British Journal of Nutrition, 84, 417-427.

Seidell, J. (1998). Dietary fat and obesity: An epidemiologic perspective. American Journal of Clinical Nutrition, 67, 546S-550S.

Shapiro, S. K., Quay, H. C., Hogan, A. E., \& Schwartz, K. P. (1988). Response perseveration and delayed responding in undersocialized aggressive conduct disorder. Journal of Abnormal Psychology, 3, 371-373.

Sigal, J. J., \& Adler, L. (1976). Motivational effects of hunger on time estimation and delay of gratification in obese and nonobese boys. Journal of Genetic Psychology, 128, 7-16.

Silvertoinen, K., Sans, S., Tolonen, H., Monterde, D., Kuulasmaa, K., Kesteloot, H., et al. (2004). Trends in obesity and energy supply in the WHO MONICO Project. International Journal of Obesity, 28, 710-718.

Skinner, J. D., Bounds, W., Carruth, B. R., Morris, M., \& Ziegler, P. (2004). Predictors of children's body mass index: A longitudinal study of diet and growth in children aged 2-8 y. International Journal of Obesity, 28, 476-482.

Solanto, M. V., Abikoff, H., Sonuga-Barke, E., Schachar, R., Logan, G. D., Wigal, T., et al. (2001). The ecological validity of delay aversion and response inhibition as measures of impulsivity in AD/HD: A supplement to the NIMH Multimodal Treatment Study of AD/HD. Journal of Abnormal Child Psychology, 29, 215-228.

Steiger, H., Young, S. N., Ng Yink Kin, N. M. K., Koerner, N., Isreal, M., Lageix, P., et al. (2001). Implications of impulsive and affective symptoms for serotonin function in bulimia nervosa. Psychological Medicine, 31, 85-95.

Stubbs, C. O., \& Lee, A. J. (2004). The obesity epidemic: Both energy intake and physical activity contribute. Medical Journal of Australia, 181, 489-491.

Williamson, D. A., Kelley, M. L., Davis, C. J., Ruggiero, L., \& Blouin, D. C. (1985). Psychopathology of eating disorders: A controlled comparison of bulimic, obese and normal subjects. Journal of Consulting and Clinical Psychology, 2, 161-166. 